\title{
Assessment on awareness of rational prescribing practices among medical interns in a tertiary care hospital: a questionnaire based study
}

\author{
Manasa C. R.*, Kalpana L., Veena R. M., Lavanya S. H., Bharath Kumar V. D.
}

Department of Pharmacology, BGS GIMS, Bengaluru, Karnataka, India

Received: 11 March 2019

Revised: 26 March 2019

Accepted: 06 April 2019

*Correspondence to:

Dr. Manasa C. R.,

Email: drmanasacr@gmail.com

Copyright: (C) the author(s), publisher and licensee Medip Academy. This is an openaccess article distributed under the terms of the Creative Commons Attribution NonCommercial License, which permits unrestricted noncommercial use, distribution, and reproduction in any medium, provided the original work is properly cited.

\begin{abstract}
Background: Awareness about rational use of Medicines is required to improve the quality of health care system. Attitude towards rational drug use is also an utmost importance as they constitute the future generation doctors.

Methods: A set of 13 questionnaire is given to the interns through an online link to their e-mail which contains informed consent and questionnaires. Respondents has to select the best suitable option and after which the data will be compiled and statistically analyzed.

Results: Age of the study participants range from 22-26yrs. Half of them have finished major postings. Almost $96.1 \%$ of them were aware of the term essential drugs. Only $25 \%$ of them said that they have NLEMI at work place, $75 \%$ of them were aware of the term Rational use of Medicines. Only $32 \%$ of them were aware of the term P drugs. $44 \%$ of them were aware of STEP criteria for selection of drug and $47 \%$ of them were aware of the updated prescribing format. $8 \%$ knew the difference between old and new prescription format, $25 \%$ of them always prescribe. Almost $82 \%$ of them narrate regarding the disease and drug therapy, $31 \%$ of them prescribe only generic name.

Conclusions: Educational intervention like CME and practical hands on training in Rational use of Medicines would help them in better understanding of the subject and its clinical implications thereby decreasing the prescribing errors.
\end{abstract}

Keywords: Internship, National list of essential medicines, Prescribing practices, Rational use of medicines

\section{INTRODUCTION}

Internship is a phase of coaching wherein a candidate is expected to conduct actual practice of medical and healthcare in an organization and acquires skills under the supervision so that they become capable of functioning independently. ${ }^{1}$

Prescription writing plays a decisive role in current health care system. Each part of the prescription is very crucial in prescribing a drug. Decision-making and proper transcribing are quintessential attributes of writing an ideal prescription. $^{2}$
Rational use of medicines (RUM) is recognized as a vital factor in health policy where patients receive medications applicable to their clinical needs, in doses that meet their own individual requirements, for an adequate period of time, and at the lesser cost to them and their community. ${ }^{3}$

The overuse, underuse or misuse of medicines ends up in wastage of scarce resources and widespread health hazards. To promote rational use of drugs, World Health organization has emphasized treatment of diseases by the use of essential drugs, prescribed by their generic names. ${ }^{3}$ Essential medicines (EM), a corner stone of RUM defined as those that satisfy the health care needs of the majority 
of a population. This concept was defined in 1975 by the WHO as a major step towards promoting RUM. ${ }^{4} 20^{\text {th }}$ National list of essential Medicines (NLEM) 2017 narrates a sum of 433 drugs deemed essential for addressing the most crucial public health needs globally. The $20^{\text {th }}$ List also provides new recommendations on which antibiotics to use for common infections and which to preserve for the foremost serious syndromes, based on a thorough review of all essential antibiotics. ${ }^{5}$

Interns should also know the concept of P-drugs and should be selected from NLEM as they will be based on good scientific evidence and consensus between experts. ${ }^{6}$ Incorporating P-drug concept in an undergraduate clinical pharmacology curriculum can aid the students to acquire knowledge on principles of rational evaluation of accessible therapeutic options and form a well informed and rational decision concerning drug treatment for an individual patient $\mathrm{P}$ drug enables doctor to prevent repeated searches of good drugs and one can know their effects and side effects thoroughly. ${ }^{6,7}$

Medical interns should be periodically assessed on prescribing knowledge and skills during their training as a means of minimizing prescribing errors. Students should know the WHO 6 steps of rational prescribing which guide to prepare UG doctors in the approach of rational prescribing. The six steps are as follows:

- Step 1: Define the patient's problem

- Step 2: Specify the therapeutic objective

- $\quad$ Step 3: Verifying the suitability of P drug

- $\quad$ Step 4: Write the prescription

- Step 5: Give instructions and warnings to the patient

- Step 6: Monitor/stop the treatment.

Their attitude toward good prescribing, rational drug use is also an utmost importance as they constitute the future generation of doctors. They should know how to prescribe safely and their attitudes, skills and knowledge needed to make good prescribing decisions should be inculcated. ${ }^{8,9}$

Awareness about rational use of Medicines is required to improve the quality of health care system. Hence the current study has been taken to assess the interns with rational prescribing practice

Since there are only few studies done on awareness of rational prescribing practices on interns, current study has been taken to assess the awareness about rational prescribing practices among medical interns.

\section{METHODS}

Descriptive Study was planned and executed by the department of Pharmacology, BGS Global institute of medical sciences, Bengaluru, Karnataka during September 2018, among undergraduate MBBS interns prior permission was obtained from the Institutional Ethics Committee (IEC).

\section{Study population}

There are 120 interns of which 35 interns belong to odd batch.

\section{Inclusion criteria}

Those Interns who have completed minimum 6 months of internship.

\section{Exclusion criteria}

Interns who are not willing to participate in the study.

Finally, 76 Interns were interested to participate in the study and were given pre-validated questionnaire. Interns were instructed not to reveal their identity in the questionnaire.

A set of 13 semi structured prevalidated questionnaire is given to the interns through an online link to their e-mail which contains informed consent and questionnaires. Respondents has to select the best suitable option and click the submit button, after which the data will be compiled and statistically analyzed.

\section{Statistical analysis}

Data will be compiled using MS excel and analyzed using statistical software. Descriptive statistical analysis will be carried out in the present study.

\section{RESULTS}

Out of 85 interns, 76 of them gave consent to the study and submitted completed questionnaire through online link sent to them. Of 76 interns, $21(27.6 \%)$ are male and 55 $(72.4 \%)$ are female. Age of the study participants range from 22-26 yrs.

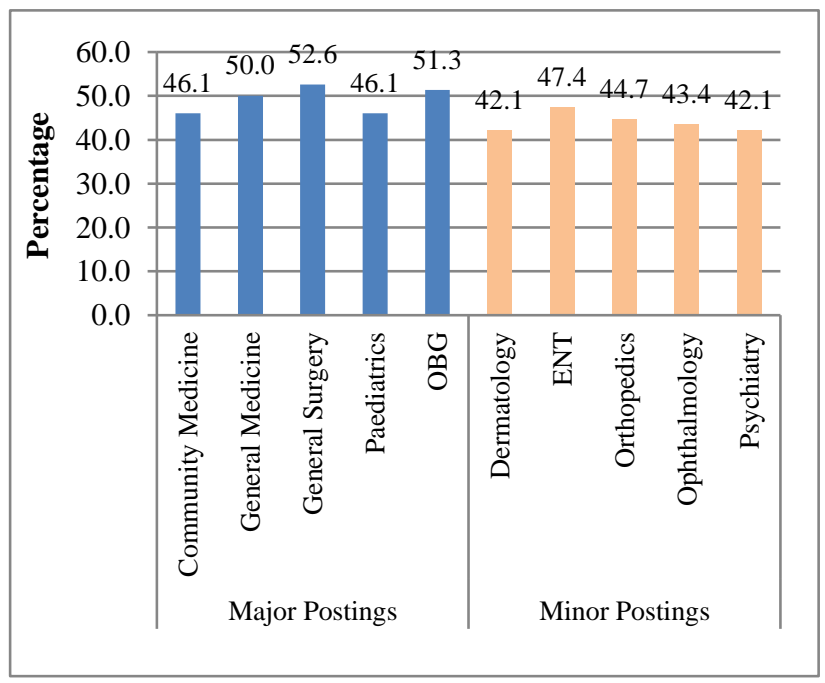

Figure 1: Internship postings completed before the survey. 
Half of them had finished major postings i.e., (46.1\%) Community medicine, (50\%) General medicine, $(52.6 \%)$ General surgery, (46.1\%) Pediatrics, (51.3\%) OBG and remaining half minor postings like $(42.1 \%)$, Dermatology, $(47.4 \%)$ ENT, (44.7\%) Orthopedics, (43.3\%) Ophthalmology and (42.1\%) Psychiatry (Figure 1).

Table 1: Intern's knowledge on rational use of medicines.

\begin{tabular}{|lllll|}
\hline $\begin{array}{l}\text { Interns' knowledge of } \\
\text { rational use of medicines }\end{array}$ & N & $\%$ & N & $\%$ \\
\hline $\begin{array}{l}\text { Are you Aware of the term } \\
\text { essential drugs }\end{array}$ & 73 & 96.1 & 3 & 3.9 \\
\hline $\begin{array}{l}\text { Do you have the NLEMI at } \\
\text { your work place? }\end{array}$ & 25 & 32.9 & 51 & 67.1 \\
\hline $\begin{array}{l}\text { Are you aware of the term } \\
\text { Rational use of Medicines? }\end{array}$ & 75 & 98.7 & 1 & 1.3 \\
\hline $\begin{array}{l}\text { Are you always aware of the } \\
\text { ingredients of the drug you } \\
\text { prescribe? }\end{array}$ & 70 & 92.1 & 6 & 7.9 \\
\hline $\begin{array}{l}\text { Are you aware of the term P- } \\
\text { drugs? }\end{array}$ & 32 & 42.1 & 44 & 57.9 \\
\hline $\begin{array}{l}\text { Are you aware of advantages } \\
\text { of using P-drug for } \\
\text { prescription? }\end{array}$ & 27 & 35.5 & 49 & 64.5 \\
\hline $\begin{array}{l}\text { Are you aware of STEP } \\
\text { criteria for selection of drug? }\end{array}$ & 44 & 57.9 & 32 & 42.1 \\
\hline $\begin{array}{l}\text { Are you aware of updated } \\
\text { prescribing format? }\end{array}$ & 47 & 61.8 & 29 & 38.2 \\
\hline
\end{tabular}

$\mathrm{N}=$ Numbers; $\%=$ Percentage

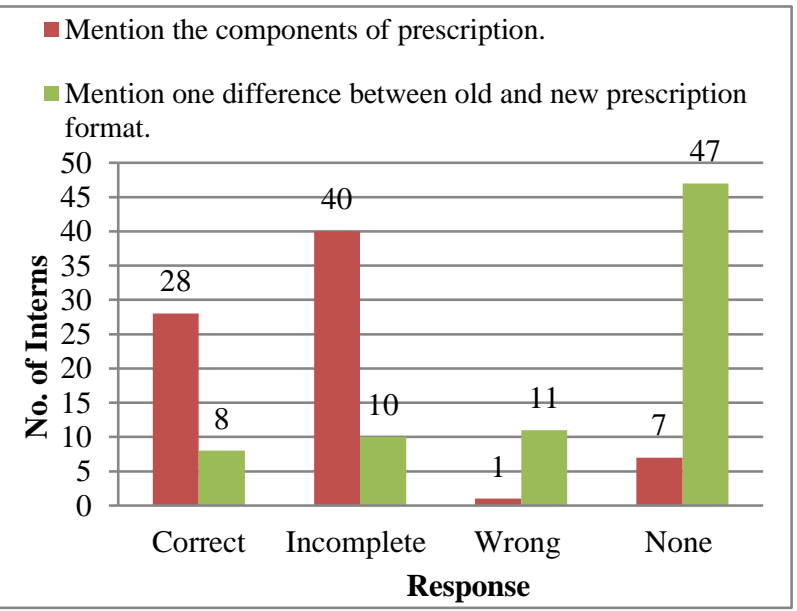

Figure 2: Responses of questions regarding $P$ drugs, components of prescription and new prescription format.

Almost $96.1 \%$ of them were aware of the term essential drugs. Only $25 \%$ of them said that they have NLEM at work place, $75 \%$ of them were aware of the term Rational use of Medicines, $70 \%$ of them are even aware of the ingredients of the drug they prescribe. Only $32 \%$ of them were aware of the term P drugs and $27 \%$ of them were aware of advantages of it. $44 \%$ of them were aware of
STEP criteria for selection of drug and $47 \%$ of them are aware of the updated prescribing format (Table 1).

Table: 2: Attitude and practice of interns regarding aspects of rational use of medicines.

\begin{tabular}{|c|c|c|c|}
\hline Parameters & $\begin{array}{l}\text { Always } \\
\mathbf{N}(\%)\end{array}$ & $\begin{array}{l}\text { Frequently } \\
\mathbf{N}(\%)\end{array}$ & $\begin{array}{l}\text { No } \\
(\%)\end{array}$ \\
\hline $\begin{array}{l}\text { Do you prescribe } \\
\text { essential medicines? }\end{array}$ & $\begin{array}{l}19 \\
(25.0)\end{array}$ & $52(68.4)$ & $\begin{array}{l}5 \\
(6.6)\end{array}$ \\
\hline $\begin{array}{l}\text { Do you inform the } \\
\text { patient regarding } \\
\text { disease, drug therapy, } \\
\text { regular follow-up and } \\
\text { monitoring of drug } \\
\text { therapy }\end{array}$ & $\begin{array}{l}63 \\
(82.9)\end{array}$ & $11(14.5)$ & $\begin{array}{l}2 \\
(2.6)\end{array}$ \\
\hline \multirow[t]{2}{*}{$\begin{array}{l}\text { What do you prefer to } \\
\text { prescribe? }\end{array}$} & $\begin{array}{l}\text { New } \\
\text { drug } \mathrm{N} \\
(\%)\end{array}$ & $\begin{array}{l}\text { Old drug N } \\
(\%)\end{array}$ & \\
\hline & $\begin{array}{l}49 \\
(64.5)\end{array}$ & $27(35.5)$ & -- \\
\hline \multirow[t]{2}{*}{$\begin{array}{l}\text { Do you prefer to use } \\
\text { prescription Pad } \\
\text { Software's / Digital } \\
\text { prescription? }\end{array}$} & $\begin{array}{l}\text { Yes } \\
\mathrm{N}(\%)\end{array}$ & $\begin{array}{l}\text { No } \\
\mathrm{N}(\%)\end{array}$ & \\
\hline & $\begin{array}{l}38 \\
(50.0)\end{array}$ & $38(50.0)$ & -- \\
\hline
\end{tabular}

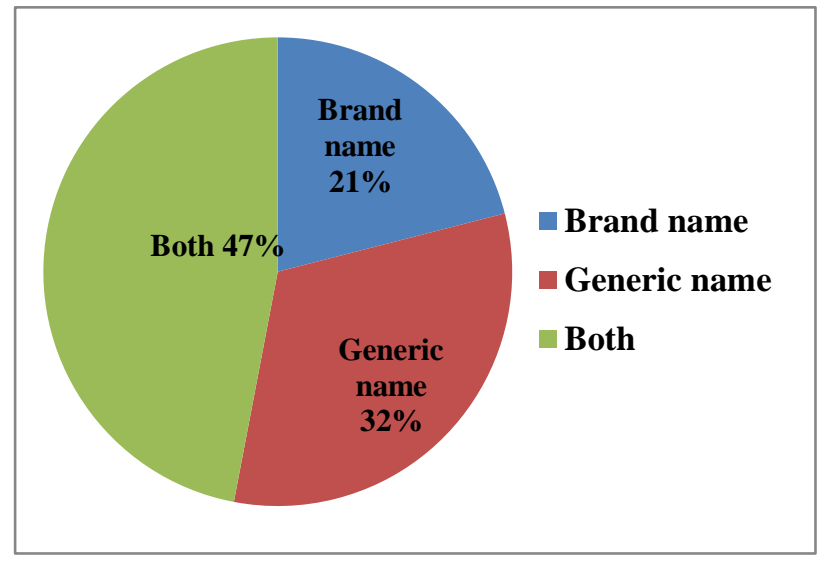

Figure 3: Interns attitude towards prescribing brand / generic name.

Only $28 \%$ of them knew the components of prescription correctly, $40 \%$ wrote incompletely, $1 \%$ wrong and $7 \%$ dint know at all (Figure 2). Only $8 \%$ knew the difference between old and new prescription format, $10 \%$ of them knew incompletely, $11 \%$ were wrong and $47 \%$ of them were unaware. $25 \%$ of them always prescribe, $68 \%$ frequently prescribe essential Medicines. Almost $82 \%$ of them narrate regarding the disease, drug therapy, and regular follow up and monitoring of drug therapy (Table 2). $64 \%$ of them prescribe new drug and $35 \%$ of them prescribe old drug to the patient. $50 \%$ of them prefer to use prescription pad software and remaining $50 \%$ of them use Digital prescription. About $21 \%$ of them write only brand name of the drug, $32 \%$ of them write only generic name 
and $47 \%$ of them write both brand and generic name in the prescription (Figure 3).

\section{DISCUSSION}

This study was designed to give the awareness to interns of BGS Global Institute of Medical Sciences, Bangalore. Application of their knowledge towards prescribing practices which is acquired during MBBS training into internship in a rational way is utmost important. Awareness on Rational use of Medicines to interns not only helps them prescribe the drugs which patient needs but also guide them to choose the drug vigilantly and cost effectively.

Half of the interns have completed major postings and remaining half minor postings, which indicate that only half of them only have been exposed or given a chance to prescribe. $96.1 \%$ of the interns knew about the term Essential Medicines which is quite more compared to a study done by Rohini Gupta where $82.9 \%$ of the interns were aware of that term. ${ }^{10}$ Just $32.9 \%$ of them tell that they have NLEM at their work place which is similar to a study done by Thiruganahalli Padmanabha Shivaraju where $33.33 \%$ knew that NLEM exists at their workplace. ${ }^{11}$ NLEM includes core list and the complementary list. ${ }^{12}$ Core list presents a list of minimum medicine needs for a basic health-care system, most efficacious, safe and economical for important conditions. The complementary list presents essential medicines for prime concern diseases, for which specifically designed diagnostic or observance facilities, and/or specialist medical care, and/or specialist coaching are needed.

In this study $42.1 \%$ were aware of term $\mathrm{P}$ drug which is more than a study done by Revathy Saravanan where only $32.08 \%$ of the interns were aware of the term $\mathrm{P}$ drug. ${ }^{13}$ This may be because of the fact that interns are quite hesitant to apply it thinking it's something new concept. $98.7 \%$ of them were aware of the term Rational use of Medicines which is in par with the study done by Ganesh Dakhale which estimates $96.5 \% .^{14}$ Irrational use leads to antimicrobial resistance, therapeutic failure or drug toxicity and wastage of resources that are already deficient in the majority of health care systems. Proper prescribing habits during the internship and that methods incorporated in the training may determine a doctor's approach towards prescribing practices which can affect his entire career. Most of them $(92.1 \%)$ were even aware of the ingredients of the drug they would prescribe which is more than a study done by Rohini Gupta. This shows their positive attitude towards learning and practice and helps them to explain the adverse effects or warning signs to the patients.

Even though medical students were exposed to this in their pharmacology curriculum during MBBS, repeated clinical case discussion, attending CME's on the same might help them come out of the dilemma. P drug or preferable drug includes drug treatment of first choice to the clinical condition with its strength, dosage forms and duration of treatment, necessary warning and information to the patients. ${ }^{15}$ Nevertheless, application of P-drug concept and its implementation along with the rational use of FDC in interns was missing. In this study $57.9 \%$ were aware of STEP criteria, where in a study done by Ganesh only $15.5 \%$ of them were aware and in a study done by Rohini Gupta $3.7 \%$ of them are aware of it. This shows awareness has been drastically increased among interns. $61.8 \%$ of interns initially agreed that they were aware of updated prescription format, but after assessing only $8 \%$ knew the difference between old and new prescription format. And none of the recent articles have assessed regarding the same. In the old WHO prescription format only Name, address, phone number of the prescriber, Date, Generic name of the drug, Strength, Dosage form, Total amount, Instructions, Warnings, Name, Address, Age of patient, Signature or Initials of prescriber are included. In the new WHO Medical council of India format, along with above parameters, complete postal address of the patient, weight of the patient, number of drugs, strength, dosage, duration and total quantity of drug should be written clearly including for pediatric patients and lastly all the drugs that are prescribed should be written in capital letters only to prevent misreading of the drug which in turn may lead to adverse drug reactions or fatalities. ${ }^{16}$

Only $28 \%$ of them knew the components of prescription correctly, compared to study done by Ganesh Dakhale where $48 \%$ of them knew it, i.e., Superscription, Inscription and Subscription. In a study by Sultana et al, on 978 prescriptions revealed errors in 769 prescriptions. Strength of the drug was missing for 279 drugs and 31 drugs were abbreviated wrongly. ${ }^{17}$ This shows any small change in the strength or dose which is an important component of prescription will reflect on the clinical outcome.

In a study done by Thiruganahalli Padmanabha Shivaraju $50.67 \%$ were in habit of frequently prescribing from EML which is less compared to our study where $68 \%$ frequently prescribe essential Medicines reflecting positive attitude. About $82 \%$ of them narrate regarding the disease, drug therapy, regular follow up and monitoring of drug therapy to the patient similar to a study done by Rohini Gupta where $76.8 \%$ inform to the patient. This shows that interns or doctors are more concerned about patient's emotions during their clinical condition which should be dealt carefully. This positive attitude helps in making the patient more adherent to the medication thereby faster relief from clinical outcome. Several studies show that what people think may not be a good way to predict their behaviour. ${ }^{18}$

This study reveals that only $31 \%$ of the interns prefer to write generic name. This reflects incomplete knowledge towards pharmacoeconomics. Though in the year 2017, media reports suggesting that the Prime Minister was considering legal steps to make it mandatory for doctors to prescribe medicines by generic names rather than by brand names; many are still prescribing brand names to promote 
pharmaceutical companies which are making products beyond affordable limit. ${ }^{19-21}$

Also one should watch whether prescription of a new drug is effective, economical compared to an old drug for a given clinical condition. In this study $64 \%$ of them prescribe new drug and $35 \%$ of them prescribe old drug to the patient, the reason being unexplained, major limiting factor indeed. In this study interns have equal preferences to both prescription pad software and Digital prescription, which is nearly similar to a study done by Revathy saravanan where $47.6 \%$ prefer Digital prescription and $52.4 \%$ prefer Prescription pad software. Most appealing benefits include augment patient safety and reduced medication errors, reduced drug costs with FDS software, easy access to patient medication records, and enhanced pharmacy workflow. ${ }^{22}$ Notable disadvantages include introduction of prescription errors, poor design features of e-prescribing software, and disruptions in pharmacy workflow.

This is only an awareness study where we are asking interns that 'are they aware of these terms', on which we cannot completely rely that they know. Further studies should be done in large scale by doing a prescription audit to complete the evaluation.

\section{CONCLUSION}

Since there is gap between the second year subjects which includes Pharmacology, additional teaching during their internship, involving in CME and practical hands on training in Rational use of Medicines would help them in better understanding of the subject and its clinical implications thereby decreasing the prescribing errors.

\section{ACKNOWLEDGEMENTS}

Authors would like to acknowledge faculties of Department of Pharmacology, BGS Global Institute of Medical Sciences, Kengeri, Bengaluru, India, MBBS interns and the Management for their kind support.

Funding: No funding sources

Conflict of interest: None declared

Ethical approval: The study was approved by the Institutional Ethics Committee

\section{REFERENCES}

1. Medical Council of India. Salient features of regulations on graduate medical education. New Delhi: MCI; 1997. Available at: www.mciindia.org/know/rules_mbbs.htm. Accessed on 9th November 2018.

2. Akram A, Mohamad N, Meerah TS, ZamZam R, Abdullah D. A pilot study-an action research to acquire clinical skill. Procedia-Social and Behavioral Sciences. 2012 Oct 17;60:236-40.
3. World Health Organization. The Pursuit of Responsible Use of medicines: Sharing and Learning from Country Experiences. Available at: http://aps.who.int/iris/bitstream/10665/75828/1/who_ emp_2012.3_eng.pdf. (Accessed on 18th November 2018).

4. The Selection of Essential Medicines - WHO Policy Perspectives on Medicines, No. 004, June 2002. Available at: http://apps.who.int/medicinedocs/pdf/s2296e/s2296e. pdf

5. National essential list of Medicines. Sophie pilan, F Baud, M. C Bottineau et al; Published by Medicines' sans Frontiers; 2017.

6. Manikandan S, Gitanjali B. National list of essential medicines of India: The way forward. J Postgr Med. 2012;58(1):68-72.

7. Parmar DM, Jadhav S. The concept of personal drugs in the undergraduate pharmacology practical curriculum. Indian J Pharmacol. 2007;39(3):165-7.

8. De Vries TPGM, Henning RH, Hogerzeil HV, Fresle DA. WHO Action Programme on Essential Drugs. Guide to good prescribing: a practical manual. World Health Organization. Available at: http://www.who.int/iris/handle/10665/59001.

Accessed 7 February 2019.

9. Naik M, Nerurkar R, Phatak A, Panchal S, Paunikar A. A questionnaire-based study to assess rational prescribing practice among interns. Nati J Physiol Pharm Pharmacol. 2015;5(4):323.

10. Gupta R, Malhotra A, Malhotra P. Assessment of rational prescribing practice among interns: a questionnaire based observational study. International J Rese Med Scien. 2018 Aug;6(8):2808-12.

11. Shivaraju TP, Savkar MK. Awareness of rational use of medicines among interns at rural teaching hospital. Int J Basic Clin Pharmacol. November 2018;7(11):2184-8.

12. Annex $1,19^{\text {th }}$ WHO Model List of Essential Medicines April 2015. Available at: https://www.who.int/medicines/publications/essential medicines/EML2015_8-May-15.pdf, Accessed on 28th Dec 2018.

13. Saravanan R, Sakthibalan M, Meher BR. Effect of educational intervention on the knowledge and attitude on prescribing amongst interns of a tertiary care hospital: A questionnaire based study. Int J Basic Clin Pharmacol. March-April 2016;5(2):366-73.

14. Dakhale G, Pimpalkhute S, Bajait C. Evaluation of Knowledge, Attitude and Practice of Rational use of Medicine Among Interns and Resident Doctors in a Tertiary Care Teaching Hospital. J Young Pharmaci. 2016;8(2):114-7.

15. Srinivasan S. A network for the rational and ethical use of drugs. Indian J Med Ethics. 2004;1(1).

16. Medical Council of India. Model prescription format for the purpose of making prescription by the registered medical practioners. Available at: http://www.delhimedicalcouncil.org/pdf/modalprescr iption.pdf. Accessed on 4th Jan 2019 
17. Sultana F, Rahman A, Paul TR, Sarwar MS, Islam MA, Rashid M. Prescribing patterns and prescription errors: a study at a tertiary care hospital of Bangladesh. Bangladesh Pharm J. 2015;18(1):20-4.

18. Norris P, Herxheimer A, Lexchin J, Mansfield P, World Health Organization. Drug promotion: what we know, what we have yet to learn: reviews of materials in the WHO/HAI database on drug promotion. Geneva: World Health Organization; 2005.

19. Ray K. Prescription can have brand name of drugs. Deccan Herald. 2017;70(132):12.

20. Jyothi Datta PT. Generic names: common cause, different solutions. Business Line. 2017;24(110):5.

21. Mani V, Phadnis A. Staff crunch stands in way of generic drugs push. Business Standard. 2017;XIX(217):12.
22. Porterfield A, Engelbert K, Coustasse A. Electronic prescribing: improving the efficiency and accuracy of prescribing in the ambulatory care setting. Perspectives in Health Information Management. 2014;11(Spring).

Cite this article as: Manasa CR, Kalpana L, Veena RM, Lavanya SH, Kumar BVD. Assess the awareness of rational prescribing practices among medical interns in a tertiary care hospital: a questionnaire based study. Int J Basic Clin Pharmacol 2019;8:1096-101. 